\title{
Optical Emission Spectroscopy of Microwave (915 MHz) Plasma in Atmospheric Pressure Nitrogen with Addition of Ethanol Vapour
}

\author{
R. MIOTK ${ }^{a, *}$, M. JASIŃSKI ${ }^{a}$ AND J. MizerACZYK ${ }^{a, b}$ \\ ${ }^{a}$ Centre for Plasma and Laser Engineering, The Szewalski Institute of Fluid-Flow Machinery \\ Polish Academy of Sciences, J. Fiszera 14, 80-231 Gdańsk, Poland \\ ${ }^{b}$ Department of Marine Electronics, Gdynia Maritime University, Morska 81-87, 81-225 Gdynia, Poland \\ In this paper results of optical emission spectroscopic study of microwave $915 \mathrm{MHz}$ plasma in atmospheric \\ pressure nitrogen with an addition of ethanol vapour are presented. The plasma was generated in waveguide- \\ -supplied cylinder-type nozzleless microwave plasma source. The aim of research was to determine the rotational \\ $T_{\text {rot }}$ and vibrational $T_{\text {vib }}$ temperatures of $\mathrm{CN}$ and $\mathrm{C}_{2}$. A method called bubbling was employed to introduce alcohol \\ (ethanol) into the plasma. The $T_{\text {rot }}$ and $T_{\text {vib }}$ were determined by comparing the measured and simulated spectra. \\ Obtained rotational and vibrational temperatures of $\mathrm{CN}$ and $\mathrm{C}_{2}$ were ranged from 4400 to $5400 \mathrm{~K}$ and from 2800 \\ to $3400 \mathrm{~K}$, respectively, depending on the location in the plasma and the microwave absorbed power $P_{\mathrm{A}}$.
}

DOI: $10.12693 /$ APhysPolA.125.1329

PACS: $52.50 . \mathrm{Sw}, 52.70 . \mathrm{Kz}$

\section{Introduction}

Hydrogen is being considered as a strategic fuel for the future. This is because hydrogen can be considered as a renewable fuel which liberates a considerable quantity of energy per unit weight $(120 \mathrm{~kJ} / \mathrm{g})$ without liberating $\mathrm{CO}_{2}$ in its combustion [1-3]. Moreover, hydrogen is easily converted into electricity by fuel cells. Hence, the investigation of new hydrogen sources is of utmost importance. Microwave plasma sources (MPS) operated at atmospheric pressure seem to have a high potential for hydrogen production via hydrocarbon reforming [3-6]. Since thermal reactions play an important role in the production of hydrogen in MPS, the knowledge of the gas temperature in such plasmas is crucial for understanding the chemical kinetics of the production process and its optimization.

Optical emission spectroscopy (OES) based on plasma sources is a well-accepted technique for plasma characterization $[3,7-12]$. OES is a well-used technique because it is simple, can be used in situ and is noninvasive. In this paper spectroscopic study of microwave $(915 \mathrm{MHz})$ plasma in nitrogen with an addition of ethanol vapour is presented. The ethanol has been introduced in the nitrogen plasma environment by the bubbling method.

The study concerns determining the rotational and vibrational temperatures of $\mathrm{CN}$ (Violet system) and $\mathrm{C}_{2}$ molecules (Swan system) emitted by microwave plasma. The CN Violet system $\left(B^{2} \Sigma^{+} \rightarrow X^{2} \Sigma^{+}\right)$is frequently observed in plasma sources containing hydrocarbons and nitrogen mixture [12]. Taking into account the strong coupling between translational and rotational energy

*corresponding author; e-mail: rmiotk@imp.gda.pl

states, the temperature derived from experiments is, in a general case, close to the gas temperature [3].

\section{Experimental}

The microwave generator $915 \mathrm{MHz}$ was connected to a waveguide WR 975 system, which includes: isolator, directional couplers, 3-stub tuner and MPS with movable plunger (Fig. 1). The microwave discharge in a form of flame takes place inside waveguide-supplied cylinder-type nozzleless MPS. The MPS was based on a standard WR 975 rectangular waveguide with a section of reduced-height, preceded by tapered section. The plasma flame was generated in a quartz tube with internal/external diameters of $26 / 30 \mathrm{~mm}$. The quartz discharge tube were inserted vertically on the axis of the reduced-height waveguide wider wall and protruded below bottom waveguide wall. On the outside of the waveguide the quartz tube was surrounded by metallic tube shield with $5 \mathrm{~mm}$ slit for visualization.

A method called bubbling was employed to introduce alcohol (ethanol $99.8 \%$ purity) into the plasma at room

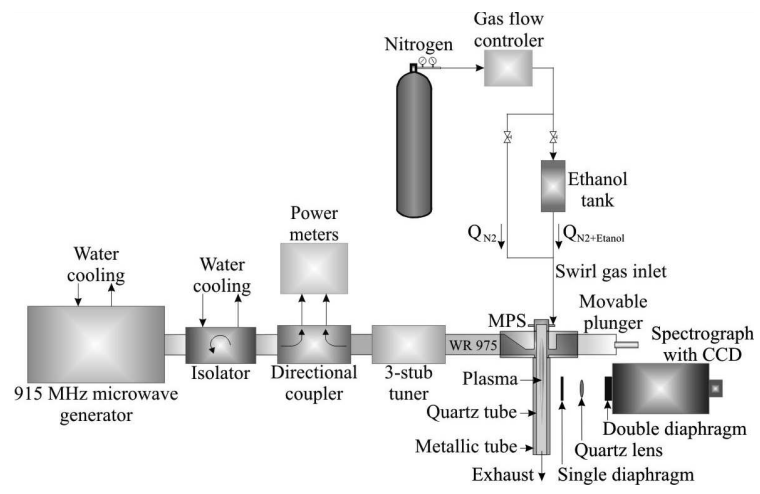

Fig. 1. Diagram of the experimental setup. 
temperature in order not to involve any additional energy in the process. The nitrogen gas flow was divided into two parts. First flow $Q_{\mathrm{N} 2}$ were only used to initiated the microwave discharge. Then nitrogen used as the carrier gas, was bubbled into the recipient containing the alcohol (ethanol tank) to drag its molecules. The resulting nitrogen-ethanol mixture $Q_{\mathrm{N} 2+\text { ethanol }}$ (gas and alcohol vapour) was introduced into the quartz discharge tube. From the rate of alcohol loss in ethanol tank as a result of nitrogen flow, we estimated that the ethanol vapour was around $3 \%$ of $Q_{\mathrm{N} 2+\text { ethanol }}$.

The plasma generation was stabilized by injecting a swirl gas in the quartz tube. The swirled gas held the plasma in the center of the tube and thus protected the quartz wall from overheating [13]. The microwave discharge was initiated by the brass rod entered to the discharge area. The absorbed microwave power $P_{\mathrm{A}}$ by the discharge was calculated as $P_{\mathrm{I}}-P_{\mathrm{R}}$, where $P_{\mathrm{I}}$ and $P_{\mathrm{R}}$ were the incident and reflected microwave powers, respectively.

To measure the plasma spectrum we used the spectrograph (DK-480 CVI with 1200 grooves/mm) equipped with CCD sensitivity calibrated camera (SBIG ST-6 $750^{*} 242$ ). A PC computer was used to control the spectrograph and acquire the data. The light emitted by the plasma was focused with a quartz lens $(50 \mathrm{~mm}$ in diameter, focal length $75 \mathrm{~mm}$ ) onto a double diaphragm with pinholes of $1 \mathrm{~mm}$ diameter at the entrance slit of the spectrometer. The width of the spectrometer entrance slit was $40 \mu \mathrm{m}$ (20 mm height). The double diaphragm was placed to collimate the light. One single diaphragm with a pinhole of $1 \mathrm{~mm}$ diameter was placed near the MPS. Using a $\mathrm{Hg}-\mathrm{Ne}$ low-pressure calibration lamp we measured that the Gaussian instrumental line profile FWHM was about $0.15 \mathrm{~nm}$.
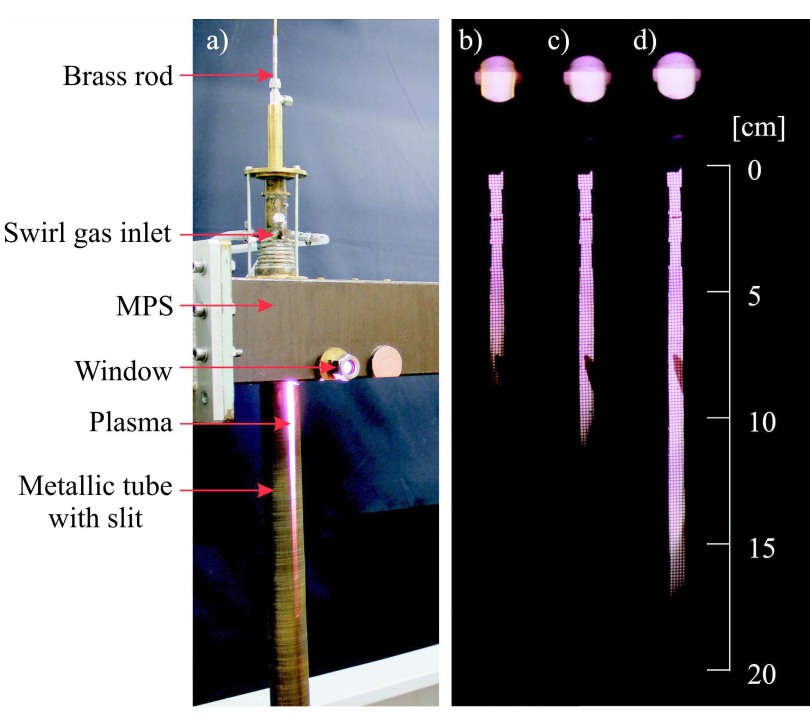

Fig. 2. (a) Photo of waveguide-supplied cylinder-type nozzleless MPS. Microwave nitrogen-ethanol mixture plasmas generated at different values of absorbed microwave power $P_{\mathrm{A}}$ : (b) $2 \mathrm{~kW}$, (c) $4 \mathrm{~kW}$, (d) $6 \mathrm{~kW}$ (nitrogen flow rate $45 \mathrm{l} / \mathrm{min}+3 \%$ ethanol vapour).
Photos of presented MPS and nitrogen-ethanol mixture plasma generated at different values of absorbed microwave power are shown in Fig. 2. The figure shows that the plasma length increases with increase of the value of absorbed microwave power. Window in the wall of the generator allow for observation of the microwave plasma inside the MPS. The slit in the metallic tube allow for observation of the plasma outside the MPS below the underside of the waveguide (BUW).

\section{Results and discussion}

All experimental tests were performed with a nitrogen flow rate from 25 to $65 \mathrm{l} / \mathrm{min}$ ( $+3 \%$ ethanol vapour) and absorbed microwave power $P_{\mathrm{A}}$ from 2 to $6 \mathrm{~kW}$. Figure 3a shows spectrum emitted by the nitrogen-ethanol mixture plasma. As seen, the dominant spectrum is $\mathrm{CN}$ Violet system. The spectrum contained also $\mathrm{C}_{2}$ Swan system. The intensity of all measured systems increased linearly with increase of microwave absorbed power. The $\mathrm{CN}$ and $\mathrm{C}_{2}$ systems only appear if the alcohol were introduced into the plasma, which indicates the existence of dissociation reactions of the ethanol molecules and, at the same time, recombination reactions which lead to the formation of these new species. Furthermore, carbon black deposit formation at the wall was observed during the operation of the nitrogen-ethanol mixture plasma. The rotational and vibrational temperatures of $\mathrm{CN}$ (Fig. 3b) and $\mathrm{C}_{2}$ (Fig. 3c) were determined by comparing the measured and simulated spectra in Lifbase [14] and Specair [15] programs, respectively. In this experiment, for the temperatures determination we used wavelength ranges as follows: $412-422 \mathrm{~nm}$ for CN Violet system and 508$518 \mathrm{~nm}$ for $\mathrm{C}_{2}$ Swan system, respectively.

The temperatures increased with increase of the microwave absorbed power (Fig. 4a). This increase was not

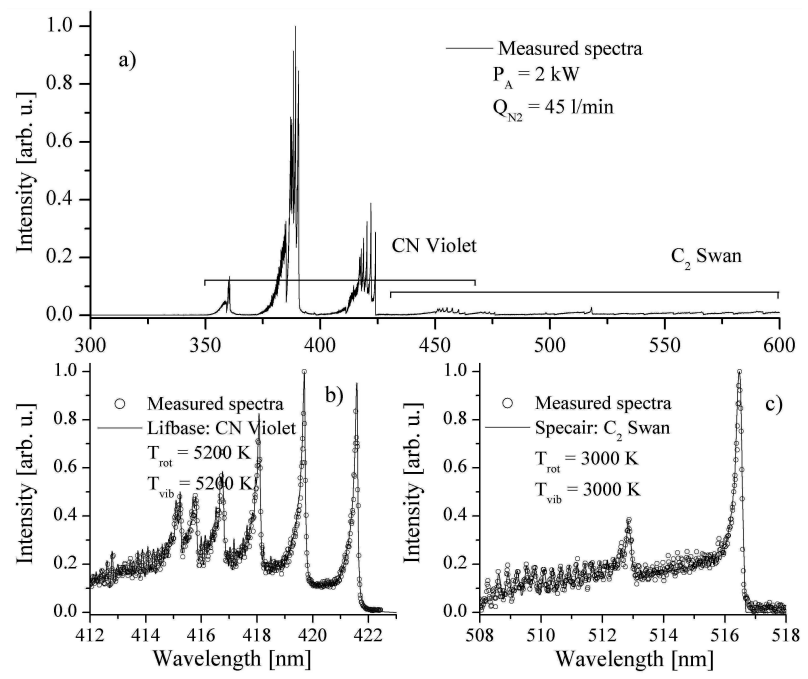

Fig. 3. (a) Measured emission spectrum of nitrogenethanol mixture plasma. Comparison of the measured and simulated emission spectra of (b) CN Violet system, (c) $\mathrm{C}_{2}$ Swan system $\left(P_{\mathrm{A}}=2 \mathrm{~kW}\right.$, nitrogen flow rate $45 \mathrm{l} / \mathrm{min}+3 \%$ ethanol vapour, measured at the height of the MPS window). 
significant as it could been seen in Fig. 2. The increase of the microwave power caused almost proportional increase of the plasma length and thus the plasma volume. It could be concluded that the microwave power influence the plasma volume and much less the plasma gas temperature. The influence of nitrogen flow rate through the ethanol tank is presented in Fig. 4b. The increase of the nitrogen flow from 25 to $65 \mathrm{l} / \mathrm{min}$ did not cause any significant changes of obtained temperatures. The rotational and vibrational temperatures of $\mathrm{CN}$ and $\mathrm{C}_{2}$ molecules as a function of distance $\mathrm{BUW}$ in nitrogenethanol mixture plasma $\left(P_{\mathrm{A}}=4 \mathrm{~kW}\right.$, nitrogen flow rate $45 \mathrm{l} / \mathrm{min}+3 \%$ ethanol vapour) are presented in Fig. $4 \mathrm{c}$. At this condition the plasma length was about $12 \mathrm{~cm}$ BUW (see Fig. 2c). Regardless the plasma length it was impossible to determine the temperature of $\mathrm{CN}$ and $\mathrm{C}_{2}$ molecules at the further area of plasma. The reason of this was low intensities of band of $\mathrm{CN}$ Violet system and $\mathrm{C}_{2}$ Swan system used for temperature determinations.

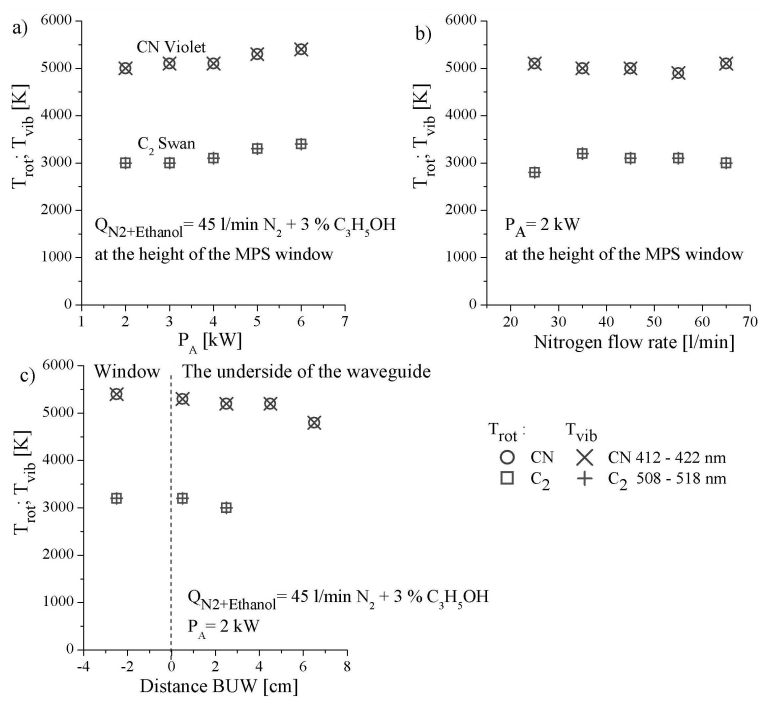

Fig. 4. Measured the rotational and vibrational temperatures of $\mathrm{CN}$ and $\mathrm{C}_{2}$ molecules as a function of: (a) microwave absorbed power $P_{\mathrm{A}}$, (b) nitrogen flow rate, (c) distance below the underside of the waveguide (distance BUW).

Obtained temperatures of $\mathrm{CN}$ and $\mathrm{C}_{2}$ were ranged from 4400 to $5400 \mathrm{~K}$ and from 2800 to $3400 \mathrm{~K}$, respectively, depending on location in the plasma and microwave absorbed power. In all conditions $T_{\text {vib }}$ were equal to $T_{\text {rot }}$ but the measured $\mathrm{CN}$ temperatures were not in agreement with the measured $\mathrm{C}_{2}$ temperatures under conditions in this study. In all cases $\mathrm{C}_{2}$ molecules provided lower temperatures than $\mathrm{CN}$ (about $2000 \mathrm{~K}$ ). This suggests the non-equilibrium plasma, whose population density does not necessarily follow a Boltzmann distribution and obtained temperatures may not provide reliable information about the gas temperature. A possible explanation of these temperatures difference between $\mathrm{CN}$ and $\mathrm{C}_{2}$ could be the mechanism of formation of these new species in the plasma. The best way to estimate the plasma gas temperature is to measure rotational spectrum of $\mathrm{OH}$ radical. However, in our study we have not registered spectrum of this particle.

\section{Conclusions}

Spectroscopic study of the microwave $915 \mathrm{MHz}$ nitrogen-ethanol mixture plasma at atmospheric pressure was presented in this work. The comparison of measured and simulated spectra of $\mathrm{CN}$ and $\mathrm{C}_{2}$ were performed and rotational $T_{\text {rot }}$ and vibrational $T_{\text {vib }}$ temperatures were determined. Obtained rotational and vibrational temperatures of $\mathrm{CN}$ and $\mathrm{C}_{2}$ ranged from 4400 to $5400 \mathrm{~K}$ and from 2800 to $3400 \mathrm{~K}$, respectively, depending on the location in the plasma, the microwave absorbed power and nitrogen flow rate.

The described MPS works very stable with various working gases at high flow rates. That makes it attractive tool for different gas processing, including conversion of liquid hydrocarbons into useful gaseous hydrocarbons and hydrogen.

\section{Acknowledgments}

This research was supported by the National Science Centre, under the programme no. 2012/05/B/ST8/ 02789 .

\section{References}

[1] J.D. Holladay, J. Hu, D.L. King, Y. Wang, Catal. Today 139, 244 (2009).

[2] O. Bicakova, P. Straka, Int. J. Hydrogen Energy 37 , 11563 (2012).

[3] M. Jimenez, R. Rincon, A. Marinas, M.D. Calzada, Int. J. Hydrogen Energy 38, 8708 (2013).

[4] M. Jasinski, M. Dors, J. Mizeraczyk, J. Power Sourc. 181, 41 (2008).

[5] M. Jimenez, C. Yubero, M.D. Calzada, J. Phys. D, Appl. Phys. 41, 175201 (2008).

[6] H. Sekiguchi, Y. Mori, Thin Solid Films 435, 44 (2003).

[7] U. Fantz, Plasma Sources Sci. Technol. 15, 137 (2006).

[8] C.O. Laux, T.G. Spence, C.H. Kruger, R.N. Zare, Plasma Sources Sci. Technol. 12, 125 (2003).

[9] A. Okada, K. Kijima, J. Phys. D, Appl. Phys. 35, 2126 (2002).

[10] R.K. Garg, T.N. Anderson, R.P. Lucht, T.S. Fisher, J.P. Gore, J. Phys. D, Appl. Phys. 41, 095206 (2008).

[11] B.N. Sismanoglu, K.G. Grigorov, R. Caetano, M.V.O. Rezende, Y.D. Hoyer, Eur. Phys. J. D 60, 505 (2010).

[12] H. Nassar, J. Phys. Conf. Series 370, 012050 (2012).

[13] H.S. Uhm, Y.C. Hong, D.H. Shin, Plasma Sources Sci. Technol. 15, 26 (2006).

[14] J. Luque, D.R. Crosley, LIFBASE: Database and spectral simulation program ( $v$ 1.6), SRI International Report MP-99-009 (1999).

[15] C.O. Laux, in: Physico-Chemical Modeling of High Enthalpy and Plasma Flows, Eds. D. Fletcher, J.M. Charbonnier, G.S.R. Sarma, T. Magin, von Karman Institute Lecture Series 2002-07, Rhode-SaintGenèse (Belgium) 2002. 